\title{
Treatment Patterns and Persistence With GLP-1 RA Treatments Among Patients With Type 2 Diabetes in France: A Retrospective Cohort Analysis
}

\author{
Sarah Zimner Rapuch • Victoria Divino - Kirsi Norrbacka • \\ Kristina Boye · Jeremie Lebrec · Myriam Rosilio • Mitch DeKoven • \\ Bruno Guerci
}

Received: December 18, 2020 / Accepted: March 26, 2021 / Published online: April 17, 2021

(C) The Author(s) 2021

\section{ABSTRACT}

Introduction: In type 2 diabetes (T2D), persistence with injectable glucose-lowering therapy is associated with better outcomes. This study used real-world pharmacy data to report on persistence with glucagon-like peptide-1 receptor agonists (GLP-1 RAs) in patients with T2D in France.

Methods: This retrospective cohort analysis presents longitudinal data from approximately 7500 French retail pharmacies that filled GLP-1-

Supplementary Information The online version contains supplementary material available at https:// doi.org/10.1007/s13300-021-01055-5.

S. Zimner Rapuch $(\bowtie) \cdot$ M. Rosilio

Lilly France, 24, Boulevard Vital Bouhot, 92521

Neuilly-sur-Seine, France

e-mail: zimner_rapuch_sarah@lilly.com

V. Divino - M. DeKoven

IQVIA, Falls Church, VA, USA

K. Norrbacka

Eli Lilly Finland, Helsinki, Finland

K. Boye

Eli Lilly and Company, Indianapolis, IN, USA

J. Lebrec

HaaPACS GmbH, Schriesheim, Germany

B. Guerci

Department of Endocrinology, Diabetology and

Nutrition, Brabois Hospital and University of

Lorraine, Vandoeuvre-Lès-Nancy, France
RA prescriptions for GLP-1 RA-naïve patients with T2D ('index therapy': dulaglutide; onceweekly exenatide [exenatide QW]; twice-daily exenatide [exenatide BID]; liraglutide) between January 2015 and December 2016 (followup $\geq 12$ months). The main outcome was treatment persistence (absence of discontinuation [gap following index therapy prescription $\geq 2$-fold the expected duration of that prescription] or switch [new non-index glucoselowering prescription issued $\leq 30$ days before/ after index therapy discontinuation]). Persistence was calculated as the median duration through Kaplan-Meier survival analysis over the variable follow-up period and as the proportion of patients persistent at 12 months. In addition to persistence outcomes (discontinuation/ switch), three other treatment modifications were assessed: augmentation/intensification with a new non-index glucose-lowering therapy; off-label dose increase (daily dose $>20 \mu \mathrm{g}$ for exenatide BID; two consecutive prescriptions with daily dose $>1.8 \mathrm{mg}$ for liraglutide); and off-label dose decrease (two consecutive prescriptions with average daily dose lower than the index dose). Off-label dose changes were not assessed for dulaglutide or exenatide QW (as single-dose, prefilled pens).

Results: Median persistence was longest for dulaglutide (373 days) versus liraglutide (205 days), exenatide QW (184 days) and exenatide BID (93 days). Twelve months after treatment initiation, the percentage of 
persistent patients ranged from 51\% (dulaglutide) to $21 \%$ (exenatide BID). Overall, treatment modification occurred less commonly for dulaglutide than for the other index GLP-1 RAs. Conclusion: This analysis revealed marked differences in persistence among GLP-1 RAs, which was highest for dulaglutide and lowest for exenatide BID. The prospective TROPHIES study will provide additional information about persistence with dulaglutide and liraglutide, including reasons for treatment modifications.

\section{PLAIN LANGUAGE SUMMARY}

Patients with type 2 diabetes (T2D) who continue to take injectable glucose-lowering therapy for the duration of time recommended by their physician (i.e. those who are 'persistent') usually have better outcomes than those who do not. Persistence may be quantified as the "the duration of time from initiation to discontinuation of therapy". Glucagon-like peptide-1 receptor agonists (GLP-1 RAs) are glucoselowering agents that are often used as the first injectable drug if oral treatments are no longer effective. The aim of the current study was to use data from approximately 7500 retail pharmacies to report persistence with each of four GLP-1 RAs (dulaglutide, once-weekly exenatide [exenatide QW], twice-daily exenatide [exenatide BID] or liraglutide) in GLP-1 RA-naïve patients with T2D in France. Patients $(N=$ $15,074)$ initiated treatment between January 2015 and December 2016 and were followed for $\geq 12$ months. The total duration of follow-up varied among patients. Among patients, persistence over the variable follow-up period was highest for dulaglutide and lowest for exenatide BID: median persistence was longer for dulaglutide (373 days) than for liraglutide (205 days), exenatide QW (184 days) or exenatide BID (93 days). Twelve months after treatment initiation, the percentage of persistent patients ranged from $51 \%$ (dulaglutide) to $21 \%$ (exenatide BID), with intermediate values for exenatide QW (35\%) and liraglutide (36\%). This analysis has revealed marked differences in the persistence of patients for various GLP-1 RAs, with patients on dulaglutide showing the highest persistence and those on exenatide BID the lowest.

Keywords: Discontinuation; France; Glucagonlike peptide-1 receptor agonist; Persistence; Pharmacy claims database; Type 2 diabetes

\section{Key Summary Points}

\section{Why carry out this study?}

In patients with type 2 diabetes (T2D), persistence with injectable glucoselowering therapy is associated with better outcomes.

The aim of this study was to report realworld persistence with four glucagon-like peptide-1 receptor agonists (GLP-1-RAs) (dulaglutide, exenatide once weekly [QW], exenatide twice daily [BID], and liraglutide) in patients with T2D in France.

\section{What was learned from this study?}

Persistence over the variable follow-up was highest for dulaglutide and lowest for exenatide BID.

Median persistence was markedly longer for dulaglutide (373 days) than for the other three GLP-1 RAs (liraglutide 205 days; exenatide QW 184 days; exenatide BID 93 days).

Twelve months after treatment initiation, the percentage of persistent patients ranged from $51 \%$ (dulaglutide) to $21 \%$ (exenatide BID), with intermediate values for exenatide QW (35\%) and liraglutide (36\%). 


\section{DIGITAL FEATURES}

This article is published with digital features, including a summary slide and plain language summary, to facilitate understanding of the article. To view digital features for this article go to https://doi.org/10.6084/m9.figshare.14308 688.

\section{INTRODUCTION}

People with diabetes require individualized treatment in order to normalize glycaemia and to prevent and address complications. Among the available treatments for type 2 diabetes (T2D), the glucagon-like peptide-1 receptor agonists (GLP-1 RAs) are considered by the American Diabetes Association and the European Association for the Study of Diabetes to be the best option for initiation of injectable therapy [1-3]. The Haute Autorité de Santé (HAS) guidelines, which provide clinical treatment recommendations for T2D in France, recommend that GLP-1 RAs should be prescribed in combination with oral glucose-lowering therapies (OADs), in patients whose glycosylated haemoglobin (HbA1c) is $>1 \%$ above target and who have a body mass index (BMI) $\geq 30 \mathrm{~kg} / \mathrm{m}^{2}$, or in those for whom weight gain or hypoglycaemia is a concern [4].

Persistence, which is defined as the act of continuing to take treatment for the prescribed duration [5], is influenced by several factors. These include perceived treatment benefit, side effect profile [6], frequency and route of administration [7]. Persistence with injectable glucose-lowering therapy is associated with better glycaemic control [8-10]. In contrast, poor persistence with glucose-lowering medications can increase the risk of long-term complications in patients with $\mathrm{T} 2 \mathrm{D}$, leading to worse health status $[11,12]$.

Many publications on persistence describe data from healthcare databases in the USA. The primary aim of this study was to use real-world pharmacy claims to report persistence with GLP-1 RAs in patients with T2D in France. Treatment dosing patterns and the use of concomitant therapies were also reported by documenting treatment augmentation/intensification, and off-label dose increases and decreases.

\section{METHODS}

The methods used in this retrospective cohort analysis of a French longitudinal retail pharmacy database (IQVIA Real World Data [RWD] Adjudicated Pharmacy Claims) have already been published as part of an analysis of data from six countries [13]. While the results of this larger multi-country analysis have been reported, we focus in more detail on the analysis for France in this paper. Included here are aspects of the methodology that are relevant for an understanding of the results or that relate specifically to France. During the study period, the IQVIA Real-World Pharmacy ClaimsFrance Database covered approximately 7500 pharmacies distributed across France and captured $35 \%$ of all retail prescriptions in the country.

Patient consent and ethics approval were not required for the use of these anonymized prescription data. The authors had permission to access the data from the IQVIA Real World Data [RWD] Adjudicated Pharmacy Claims database. Permission was granted by IQVIA.

\section{Patient Selection and Index Therapy Criteria}

Eligibility criteria have been published previously [13]. Adults who had $\geq 1$ claim for an $\mathrm{OAD}$ in the 6-month baseline period (proxy for diagnosis of T2D) and who were naïve to the GLP-1 RA therapy class were included in the analysis if they received a prescription for a GLP-1 RA (the 'index therapy') that was available in France for treatment of T2D between 1 January 2015 and 31 December 2016. The eligible index therapies were dulaglutide, onceweekly exenatide (exenatide QW), twice-daily exenatide (exenatide BID) and liraglutide. Dulaglutide was administered once weekly and liraglutide once daily. Fixed-dose GLP-1 RA/insulin combination treatments were not included as index therapies. The date on which the 
index therapy was prescribed was termed the 'index date'. Patients were followed for a minimum of 12 months to the end of the available study data or the end of the study period (31 December 2017), whichever came first.

\section{Patient Characteristics and Prescribers}

We report patient demographic characteristics (age and gender), prescriber specialty and follow-up time, as well as average daily dose (ADD) or average weekly dose (AWD) (for index therapies administered daily or weekly, respectively) by year of prescription and by month for up to 6 months after the index prescription.

\section{Outcome Measures}

Persistence, the main outcome, was calculated for each index therapy using two analytical approaches: median duration derived through Kaplan-Meier (KM) survival analysis over the variable follow-up period and the proportion of patients persistent at 12 months. Patients were considered persistent until there was evidence of GLP-1 RA discontinuation or switch, whichever occurred first. Discontinuation was defined as a gap following an index therapy prescription $\geq 2$-fold the expected duration of that prescription. (The reasons for discontinuation are not available in such claims data.) Switch was defined as a new non-index glucose-lowering prescription issued $\leq 30$ days before or after discontinuation of the index therapy. A new non-index glucose-lowering treatment could be a non-index GLP-1 RA or a new glucose-lowering therapy class not prescribed in the pre-index period, including a fixed-dose GLP-1 RA/insulin combination. Changing to a fixed-dose GLP-1 $\mathrm{RA} /$ insulin combination was still regarded as a switch if the combination treatment incorporated the same GLP-1 RA as the index treatment.

In addition to discontinuation and switch, three other treatment modifications were reported in the analysis: augmentation/intensification, off-label dose increase and off-label dose decrease. Augmentation/intensification was defined as a new non-index glucose- lowering therapy started $\geq 30$ days before the end of follow-up or the index therapy discontinuation date, in addition to the index therapy. An off-label dose increase was defined as a dose increase outside of the label recommendations (daily dose $>20 \mu \mathrm{g}$ for exenatide BID; two consecutive prescriptions with daily dose $>$ $1.8 \mathrm{mg}$ for liraglutide); an off-label dose decrease was defined as two consecutive prescriptions with the ADD lower than the index dose. Off-label dose changes were not assessed for patients on dulaglutide or exenatide QW as these treatments are available only as singledose, prefilled pens that provide no option for dose titration. Time to first treatment modification (defined as a composite of discontinuation, switch, augmentation/intensification, offlabel dose increase and off-label dose decrease) was estimated using KM survival analysis. In addition, the proportion of patients who experienced modification of each category of first treatment (discontinuation; switch; augmentation/intensification; off-label dose increase; offlabel dose decrease) 6 and 12 months after treatment initiation (i.e. the 'index date') were reported. For patients who switched index therapy or whose index therapy was augmented/intensified over the variable follow-up period, we determined the glucose-lowering class to which they switched/that was used for augmentation/intensification.

\section{Previous and Concomitant Therapies}

Glucose-lowering therapies that were prescribed in the 180-day pre-index period (but not on the index date) were summarized, as were non-index glucose-lowering therapies initiated on the index date but not prescribed in the 180-day pre-index period. A non-index glucose-lowering therapy class was considered concomitant if the time between prescriptions in the pre- and postindex was $<120$ days, or if the therapy class was dispensed on the index date.

\section{Analysis}

All data were analysed descriptively (frequency and percentage distribution for categorical 
variables; mean and standard deviation/median and range, 95\% confidence interval $[\mathrm{CI}]$ or interquartile range for continuous and count variables). KM survival analysis was used for estimating index therapy persistence and time to first modification of the index treatment over the variable follow-up period. SAS v9.2 or above software (SAS Institute, Cary, NC, USA) was used for all analyses; no formal statistical tests were employed. Further details related to the methods used in this analysis can be found in previous publications [13-15].

\section{RESULTS}

\section{Patient and Prescriber Characteristics}

The final sample comprised 15,074 patients (dulaglutide 3464; exenatide QW 3111; exenatide BID 487; liraglutide 8012). Patient age was similar among treatment groups, with median values of just over 60 years. Males outnumbered females in all index therapy groups (Table 1).

Overall, fewer patients had their GLP-1 RA prescribed by an endocrinologist/diabetologist (range $12-25 \%$ ) than by a general practitioner (GP; $29-57 \%$ ) or a hospital physician (21-40\%). However, the specialty of the prescribing physician differed among groups: exenatide (QW and BID) was predominantly prescribed by GPs; liraglutide was prescribed equally by GPs and hospital physicians; and dulaglutide was prescribed more frequently by hospital physicians than by GPs (Table 1).

\section{Previous and Concomitant Therapies}

The majority of patients (86-98\%) received glucose-lowering therapy in the 180-day period prior to the index date. In all groups, the two most common previously prescribed glucoselowering therapies were sulfonylurea (49-61\%) and biguanide (60-64\%); other commonly prescribed therapies were basal insulin (16-36\%), dipeptidyl peptidase (DPP)-IV inhibitors (22-29\%) and the combination therapy DPP-IV inhibitor + biguanide (24-45\%). The majority of patients $(68-77 \%)$ did not initiate a new concomitant OAD or glucose-lowering medication at the same time as the index therapy. Among those who did initiate an OAD, a biguanide was the most common treatment (20-25\% of patients in each index therapy cohort) followed by sulfonylureas (3-13\%).

\section{Index Therapy: Average Daily and Weekly Doses}

With one exception, ADD and AWD of the index therapies remained relatively stable over the first 6 months of therapy and from 2015 to 2017. The exception was the ADD of liraglutide, which increased from $1.32 \mathrm{mg}$ (days 0-30) to $1.47 \mathrm{mg}$ (days 151-180) and from $1.41 \mathrm{mg}$ (2015) to $1.64 \mathrm{mg}$ (2017) (Table 2).

\section{Persistence}

Persistence over the variable follow-up period was highest for dulaglutide, lowest for exenatide BID and intermediate for liraglutide and exenatide QW (Fig. 1; Table 3). Median persistence was markedly longer for dulaglutide (373 days; 95\% CI 344-402 days) than for the other three index therapies (liraglutide 205 days, 95\% CI 196-215 days; exenatide QW 184 days, 95\% CI 172-197 days; exenatide BID 93 days [95\% CI 85-110 days), and there was no overlap between the $95 \%$ CI for median persistence for dulaglutide and the 95\% CIs for the other three groups (Table 3). Twelve months following treatment initiation, the proportion of persistent patients ranged from $51 \%$ for dulaglutide to $21 \%$ for exenatide BID; exenatide QW and liraglutide showed intermediate levels of persistence (35 and 36\%, respectively) (Table 3).

For all treatments, discontinuation was the most common initial treatment modification at 6 and 12 months after index therapy initiation (36-51\% of the total number of patients at 12 months) (Table 4). Switching (11-24\% at 12 months) occurred more frequently than augmentation/intensification (5-8\%) or, for exenatide BID and liraglutide only, off-label dose increases (4-8\%) or decreases (6-11\%). 
Table 1 Patient demographic characteristics, prescribing physician specialty and follow-up time

\begin{tabular}{|c|c|c|c|c|c|}
\hline \multirow{2}{*}{$\begin{array}{l}\text { Patient and prescriber } \\
\text { characteristics and follow-up } \\
\text { time }\end{array}$} & \multicolumn{5}{|l|}{ Index therapy } \\
\hline & $\begin{array}{l}\text { All GLP-1 RA } \\
\text { recipients }(N= \\
15,074)\end{array}$ & $\begin{array}{l}\text { Dulaglutide } \\
(N=3464)\end{array}$ & $\begin{array}{l}\text { Exenatide } \\
\text { QW }(N= \\
3111)\end{array}$ & $\begin{array}{l}\text { Exenatide } \\
\text { BID }(N= \\
487)\end{array}$ & $\begin{array}{l}\text { Liraglutide } \\
(N=8012)\end{array}$ \\
\hline \multicolumn{6}{|l|}{$\operatorname{Age}^{\mathrm{a}}$ (years) } \\
\hline Median (IQR) & $62(54-68)$ & $62(55-68)$ & $62(55-69)$ & $61(54-68)$ & $61(54-68)$ \\
\hline \multicolumn{6}{|l|}{ Gender, $n(\%)$} \\
\hline Female & $6698(44.4)$ & $1523(44.0)$ & $1336(42.9)$ & $224(46.0)$ & $3615(45.1)$ \\
\hline Male & $8090(53.7)$ & $1872(54.0)$ & $1724(55.4)$ & $252(51.8)$ & $4242(53.0)$ \\
\hline Missing & $286(1.9)$ & $69(2.0)$ & $51(1.6)$ & $11(2.3)$ & $155(1.9)$ \\
\hline \multicolumn{6}{|c|}{ Specialty of prescribing physician, $n(\%)$} \\
\hline General practitioner & $6232(41.3)$ & $995(28.7)$ & $1767(56.8)$ & $257(52.8)$ & $3213(40.1)$ \\
\hline Hospital & $5206(34.5)$ & $1394(40.2)$ & $645(20.7)$ & $151(31.0)$ & $3016(37.6)$ \\
\hline Endocrinologist/diabetologist & $2824(18.7)$ & $879(25.4)$ & $517(16.6)$ & $56(11.5)$ & $1372(17.1)$ \\
\hline Unknown & $555(3.7)$ & $134(3.9)$ & $139(4.5)$ & $14(2.9)$ & $268(3.3)$ \\
\hline Other & $257(1.7)$ & $62(1.8)$ & $43(1.4)$ & $9(1.9)$ & $143(1.7)$ \\
\hline \multicolumn{6}{|l|}{ Follow-up time (months) } \\
\hline Median (range) & $22(12-36)$ & $17(12-23)$ & $23(12-31)$ & $28(12-36)$ & $25(12-36)$ \\
\hline
\end{tabular}

$B I D$ Twice daily, GLP-1 RA glucagon-like peptide-1 receptor agonist, $I Q R$ interquartile range, $Q W$ once weekly

${ }^{a}$ Age on index date

Discontinuation as first treatment modification occurred most frequently in exenatide BIDtreated patients $(51 \%$ of the total number of patients at 12 months), and least commonly in those receiving the weekly treatments (dulaglutide 36\%; exenatide QW 38\%).

Over the variable follow-up period, among the patients who switched, the majority (86-89\%) switched to one class of glucose-lowering therapy only. Among these patients, the pattern of switching was different for dulaglutide versus the other three GLP-1 RAs: those whose index therapy was exenatide QW, exenatide BID or liraglutide most commonly switched to a different GLP-1 RA (44-63\% of switches), with a lower proportion switching to basal insulin (18-22\%). In contrast, those whose index therapy was dulaglutide showed a similar rate of switching to basal insulin or a different GLP-1 RA (26 and 23\%, respectively). No dulaglutide-treated patient switched to exenatide BID, and liraglutide was favoured over exenatide QW. Among the patients who switched, switching to a GLP-1 RA/insulin fixeddose combination therapy was substantially more common in patients whose index therapy was dulaglutide $(17 \%)$ than in those whose index therapy was exenatide or liraglutide (3-13\%).

\section{Patients Experiencing Each Category of Treatment Modification}

The weekly treatments (dulaglutide and exenatide QW) showed a higher proportion of patients without treatment modification at both 6 and 12 months than the once- or twicedaily treatments (liraglutide, exenatide BID) (Table 4). Time to first modification of the index treatment over the variable follow-up period 
Table 2 Mean daily and weekly doses of index therapy by monthly intervals up to 6 months after initiation, and by year of prescription

\begin{tabular}{|c|c|c|c|c|}
\hline $\begin{array}{l}\text { Period after initiation and year of } \\
\text { prescription }\end{array}$ & $\begin{array}{l}\text { Dulaglutide }(N= \\
3464) \\
\operatorname{Dose}^{\mathbf{a}}(\mathrm{mg})\end{array}$ & $\begin{array}{l}\text { Exenatide QW } \\
(N=3111) \\
\operatorname{Dose}^{\mathrm{a}}(\mathbf{m g})\end{array}$ & $\begin{array}{l}\text { Exenatide BID } \\
(N=487) \\
\operatorname{Dose}^{\mathbf{b}}(\mathbf{m g})\end{array}$ & $\begin{array}{l}\text { Liraglutide }(N= \\
8012) \\
\text { Dose }^{\text {b }}(\mathrm{mg})\end{array}$ \\
\hline \multicolumn{5}{|l|}{ Period after initiation (days) } \\
\hline $0-30$ & $1.43(0.39)$ & $2.03(0.43)$ & $12.97(5.85)$ & $1.32(0.55)$ \\
\hline $31-60$ & $1.40(0.41)$ & $2.00(0.44)$ & $12.80(5.70)$ & $1.38(0.59)$ \\
\hline $61-90$ & $1.44(0.43)$ & $2.02(0.47)$ & $12.46(5.59)$ & $1.40(0.58)$ \\
\hline $91-120$ & $1.42(0.42)$ & $2.00(0.41)$ & $13.07(6.32)$ & $1.43(0.61)$ \\
\hline $121-150$ & $1.40(0.40)$ & $1.98(0.43)$ & $12.98(6.08)$ & $1.46(0.63)$ \\
\hline $151-180$ & $1.40(0.40)$ & $2.00(0.61)$ & $13.22(6.55)$ & $1.47(0.63)$ \\
\hline \multicolumn{5}{|l|}{ Year } \\
\hline 2015 & - & $2.05(0.06)$ & $12.65(0.72)$ & $1.41(0.04)$ \\
\hline 2016 & $1.44(0.03)$ & $2.00(0.02)$ & $12.83(0.36)$ & $1.49(0.03)$ \\
\hline 2017 & $1.43(0.11)$ & $2.06(0.19)$ & $14.23(0.67)$ & $1.64(0.16)$ \\
\hline
\end{tabular}

Dose data are shown as the mean with the standard deviation $(\mathrm{SD})$ in parentheses

a Average weekly dose

${ }^{b}$ Average daily dose

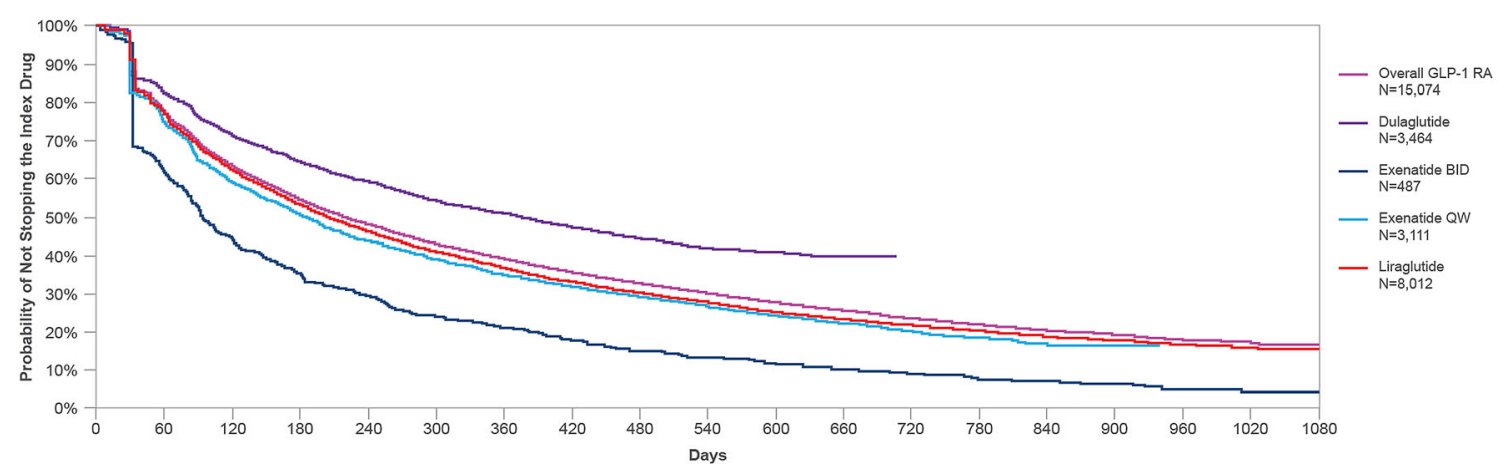

Fig. 1 Kaplan-Meier analysis for index therapy persistence (time to first discontinuation or switch) over the variable follow-up period. BID Twice daily, GLP-1 RA glucagon-like peptide-1 receptor agonist, $Q W$ once weekly

was substantially greater for patients receiving dulaglutide than for those receiving exenatide BID, exenatide QW or liraglutide (Fig. 2).

\section{DISCUSSION}

Our study reported persistence with the four index GLP-1 RA therapies for which data were available over the period January 2015 to December 2017 in France. We found that persistence at 12 months, and over the variable follow-up period, was higher for dulaglutide 
Table 3 Persistence with index therapy

\begin{tabular}{|c|c|c|c|c|c|}
\hline \multirow[t]{2}{*}{ Persistence } & \multicolumn{5}{|l|}{ Index therapy } \\
\hline & $\begin{array}{l}\text { All GLP-1 RA } \\
\text { recipients } \\
(N=15,074)\end{array}$ & $\begin{array}{l}\text { Dulaglutide } \\
(N=3464)\end{array}$ & $\begin{array}{l}\text { Exenatide QW } \\
(N=3111)\end{array}$ & $\begin{array}{l}\text { Exenatide } \\
\text { BID } \\
(N=487)\end{array}$ & $\begin{array}{l}\text { Liraglutide } \\
(N=8012)\end{array}$ \\
\hline At 12 months (\%) & 39 & 51 & 35 & 21 & 36 \\
\hline $\begin{array}{l}\text { Median (95\% CI) over the variable } \\
\text { follow-up period (days) }\end{array}$ & $220(213,228)$ & $373(344,402)$ & $184(172,197)$ & $93(85,110)$ & $205(196,215)$ \\
\hline
\end{tabular}

CI Confidence interval

Table 4 Treatment modification at 6 and 12 months after index therapy initiation

\begin{tabular}{|c|c|c|c|c|c|}
\hline $\begin{array}{l}\text { Treatment modification } \\
\text { (\% of total cohort) }\end{array}$ & $\begin{array}{l}\text { All GLP-1 RAs } \\
(N=15,074)\end{array}$ & $\begin{array}{l}\text { Dulaglutide }^{\mathrm{a}} \\
(N=3464)\end{array}$ & $\begin{array}{l}\text { Exenatide } \mathrm{QW}^{\mathrm{a}} \\
(N=3111)\end{array}$ & $\begin{array}{l}\text { Exenatide BID } \\
(N=487)\end{array}$ & $\begin{array}{l}\text { Liraglutide } \\
(N=8012)\end{array}$ \\
\hline \multicolumn{6}{|c|}{6 months after index therapy initiation } \\
\hline $\begin{array}{l}\text { No first treatment } \\
\text { modification }\end{array}$ & 43.2 & 59.3 & 47.1 & 24.2 & 35.9 \\
\hline \multicolumn{6}{|c|}{ First treatment modification } \\
\hline Discontinuation & 33.2 & 27.0 & 31.2 & 45.6 & 35.9 \\
\hline Switch & 10.1 & 7.9 & 17.0 & 17.0 & 7.9 \\
\hline $\begin{array}{l}\text { Augmentation/ } \\
\text { intensification }\end{array}$ & 4.9 & 5.9 & 4.8 & 4.5 & 4.6 \\
\hline Off-label dose increase & 2.7 & - & - & 3.3 & 4.8 \\
\hline Off-label dose decrease & 6.0 & - & - & 5.3 & 10.9 \\
\hline \multicolumn{6}{|c|}{12 months after index therapy initiation } \\
\hline $\begin{array}{l}\text { No first treatment } \\
\text { modification }\end{array}$ & 28.2 & 45.3 & 31.7 & 14.4 & 20.2 \\
\hline \multicolumn{6}{|c|}{ First treatment modification } \\
\hline Discontinuation & 41.2 & 36.2 & 38.1 & 50.5 & 43.9 \\
\hline Switch & 13.9 & 10.6 & 23.9 & 20.7 & 11.0 \\
\hline $\begin{array}{l}\text { Augmentation/ } \\
\text { intensification }\end{array}$ & 6.4 & 7.9 & 6.3 & 4.9 & 5.9 \\
\hline Off-label dose increase & 4.3 & - & - & 3.7 & 7.8 \\
\hline Off-label dose decrease & 6.1 & - & - & 5.7 & 11.2 \\
\hline
\end{tabular}

a Off-label dose changes not assessed; treatment available only as a single-dose, prefilled pen with no titration 
than for any of the other index therapies (Fig. 1; Table 3) and this difference could be observed within 1 month of treatment initiation. This finding is consistent with the results of other studies from Germany, Italy and the USA, which have found that dulaglutide shows higher persistence compared to exenatide BID, exenatide QW, liraglutide and lixisenatide [16-19].

In addition to persistence, the proportion of patients who experienced any category of first treatment modification (discontinuation, switch, augmentation/intensification, off-label dose increase and off-label dose decrease) was lower at both 6 and 12 months for the weekly treatments (dulaglutide and exenatide QW) than for the once- or twice-daily treatments (liraglutide, exenatide BID). Dulaglutide patients also experienced a longer time without treatment modification than those receiving other treatments. However, off-label dose changes were not possible with weekly treatments, and this may have influenced the difference between the once-/twice-daily treatments and the weekly treatments in the proportion of patients experiencing modifications.

The current retrospective analysis, based on pharmacy claims data, provides important information about glucose-lowering prescribing patterns in patients from France with T2D before, during and after they initiated GLP-1 RA therapy in 2015, 2016 and 2017. Our study population comprised approximately 15,000 individuals who were of similar age and gender distribution (median age 62 years; 54\% male) (Table 1) to those from a previous French national survey of people with diabetes (ENTRED 2007; mean age 65 years; 54\% male) $[20,21]$ and to the French cohort of the recent TROPHIES prospective, observational study of people with T2D who are initiating their first injectable glucose-lowering therapy with dulaglutide or liraglutide (59 years; $56 \%$ male) [22]. Due to differences among GLP-1 RAs in reimbursement start dates in France (Electronic Supplementary Material [ESM] Table S1), median follow-up time was markedly shorter for dulaglutide than for the other three GLP-1 RAs in our study (Fig. 1). However, all patients had a minimum follow-up of 12 months.

The reasons that underlie the higher persistence with dulaglutide compared with the other three GLP-1 RAs are not known. Dosing frequency could be an attribute that determines persistence, but this is not confirmed by the markedly different persistence that we observed with the two weekly treatments, dulaglutide and exenatide QW, in the current study (median persistence of 373 and 184 days, respectively). Other attributes, such as perceived treatment benefit, burden and side effect profile, are all predictors of persistence $[6,7]$. One could also hypothesize that patients expressing preference for one treatment versus another could be more persistent. Examination of the attributes of GLP-1 RAs, in particular, has shown that when differences in efficacy between medications are small, other treatment

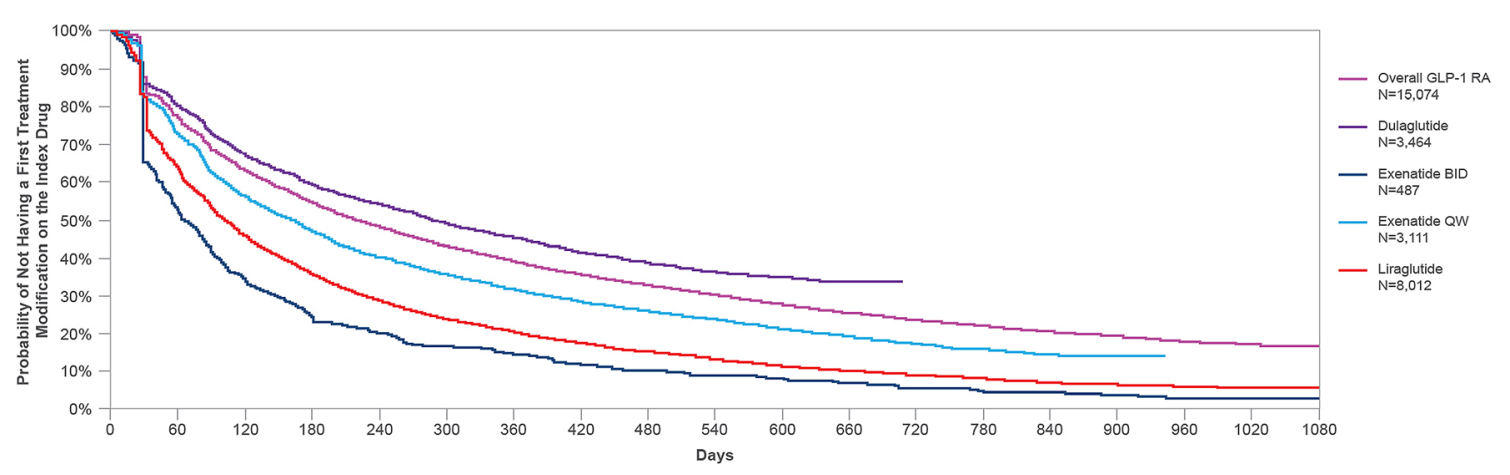

Fig. 2 Kaplan-Meier analysis for time to first modification of the index treatment over the variable follow-up period. First treatment modification comprised

discontinuation, switching, augmentation/intensification or off-label dose increase or decrease (see text for details) 
features (e.g. dosing frequency and delivery system) are of much greater importance to patients [23]. In particular, lower preferences are assigned to medications that require reconstitution, the necessity of waiting during medication preparation and needle handling $[24,25]$. The impact of the device on patient preference has been recently illustrated in a study on two treatments having the same weekly dosing frequency (dulaglutide and semaglutide): the PREFER trial [26]. Semaglutide (a GLP-1 RA that became available after the study period) is administered using a device similar to insulin pens whereas dulaglutide is administered with an auto-injector. In this randomized crossover trial, significantly more patients with T2D expressed a preference for the dulaglutide device than for the semaglutide device (84.2 vs. $12.3 \% ; P<0.0001$ ) [26]. A final factor that may influence persistence is the specialty of the prescribing physician-an association that has been documented in other conditions [27] but one that we did not analyse in our study.

In order to compare our results with published data on persistence to GLP-1 RAs in France, we performed a systematic search of the PubMed database and abstracts from scientific congresses (details available in the ESM [Literature searches]). This yielded 167 publications, of which four were relevant. Of the GLP-1 RAs, only exenatide BID and liraglutide were included in these publications; persistence was consistently higher for liraglutide than for exenatide BID. The results of the systematic literature search (ESM Table S2) show that the magnitude of persistence documented in the current analysis is lower than that reported in previous studies involving the use of liraglutide or exenatide BID in France. The difference between our results (persistence at 12 months: range 21-51\%; Table 3) and those of Roussel et al. [28] (70\%; ESM Table S2), whose study was conducted at a time when once-weekly GLP-1 RAs were not available, may be partly explained by the definitions used: discontinuation/persistence. We defined discontinuation as a gap following an index therapy prescription $\geq 2$-fold the expected duration of that prescription (generally 60 days). In contrast,
Roussel et al. [28, 29] defined persistence as the absence of a 6-month interruption of index therapy (ESM Table S2). Since there is a positive relationship between the maximum allowable gap between prescriptions that defines persistence and estimated persistence rate [30], it is not surprising that Roussel et al. [28, 29] reported higher persistence rates than the current study. However, it should be noted that Guerci et al. [31] have identified differences in persistence among real-world studies, even when the same GLP-1 RA was studied in the same country using the same definition of persistence. Differences in databases, patient populations and study methodology mean that comparisons of persistence rates among studies or countries should be interpreted with caution.

Despite these reservations, data from two studies [28, 29]-both involving French patients-show similar persistence rates for GLP-1 RAs and insulin using a discontinuation definition of 6-month interruptions in index therapy. Similar persistence rates occurred despite insulin therapy being more complex than GLP-1 RA therapy [1]. It is possible that gastrointestinal adverse events, which are a class effect of GLP-1 RAs [32], offset any advantages offered by this drug class in terms of injection frequency and convenience. However, adverse event data were not available for either of the analyses published by Roussel et al. $[28,29]$. The impression that patients may have of insulin as a 'life-saving' therapy may also contribute to patient persistence with this more complex treatment.

In the current study, discontinuation was substantially more frequent than switching as a first treatment modification (Table 4). Moreover, discontinuation as a first treatment modification occurred in a higher percentage of the exenatide BID cohort than in those receiving the other three index therapies, a finding that concurs with previously published data that showed consistently higher persistence for liraglutide than for exenatide BID [14, 15]. The magnitude of the discontinuation rate in this analysis (discontinuation was the first treatment modification at 12 months in $36-51 \%$ of patients) may be caused by the definition of switching (new non-index glucose-lowering 
prescription issued $\leq 30$ days before or after discontinuation of the index treatment). It may be that a substantial proportion of patients who 'discontinued' their index medication actually initiated therapy with another glucose-lowering medication $>30$ days after discontinuation. Given that people with T2D in France visit their GP on average 8.6 times per year [33], inter-visit gaps of $>30$ days are not uncommon and would support this possibility.

Variations in preference for prescribing the different GLP-1 RA index therapies were found among the different types of physicians. Among dulaglutide patents, a hospital physician was most often associated with the index prescription (40.2\%). Conversely, a GP was most often associated with the index prescription for the other therapy cohorts (40.1-56.8\%). Greater hesitance among GPs to prescribe dulaglutide may reflect a more conservative approach towards newer types of treatment, compared with other types of physicians (i.e. GPs may be more likely to prescribe established GLP-1 RAs that they are familiar with). In addition to drug attributes, prescribing decisions of GPs may be influenced by social/interpersonal influences, cost considerations, mode of exposure to pharmacological information, level of knowledge and specific area of interest $[34,35]$.

Patients whose index therapy was dulaglutide were as likely to switch to basal insulin as to a different GLP-1 RA; if a GLP-1 RA was chosen, liraglutide was the most frequent choice and was selected more frequently than the other weekly treatment, exenatide QW. Selection of liraglutide may have been influenced by the 2016 publication of the results of the LEADER trial, which documented a reduction in cardiovascular events in association with liraglutide therapy $(1.8 \mathrm{mg} /$ day) in patients with T2D who were at high cardiovascular risk [36]. Moreover, in 2017, liraglutide was the GLP-1 RA recommended by the French Diabetes Society (Société Francophone du Diabète) for secondary prevention of cardiovascular events [37]. The LEADER trial results and the Société Francophone du Diabète position statement may also explain the increase in ADD of liraglutide in the current study from $1.41 \mathrm{mg} /$ day in 2015 to $1.64 \mathrm{mg} /$ day in 2017 (Table 2). When looking at the reduced persistence in the liraglutide cohort, one hypothesis is that the increase in ADD could have been associated with an increase in the incidence of liraglutide-associated adverse events [38, 39]. In the current study, among patients who switched, GLP-1 RA/insulin combination therapy was a more common switch choice in the dulaglutide index therapy group than in the other three groups (17 vs. $3-13 \%)$.

iDegLira (a fixed-dose combination of a oncedaily long-acting basal insulin degludec and liraglutide; Xultophy $\left.{ }^{\circledR}\right)$ was the only insulin/ GLP-1 RA combination therapy available in France [40] during the entire period covered by this analysis. Therefore, all switches to GLP-1 RA/ insulin combination therapy involved the use of liraglutide after the change of therapy. For patients whose index therapy was dulaglutide, exenatide BID or exenatide QW, this involved a change of GLP-1 RA-an event that was universally defined as a switch. However, although classified as a switch in the study criteria, patients whose index therapy was liraglutide did not change GLP-1 RA; therefore, this treatment modification is effectively an augmentation/intensification rather than switching because it combines two molecules. The reason that this modification was not considered as an augmentation/intensification was because of an expected reduction in the dose of the liraglutide component of iDegLira, in accordance to the product label recommendations (from a liraglutide maintenance dose of 1.2 or $1.8 \mathrm{mg} /$ day [41] to the recommended daily starting dose of iDegLira of $0.6 \mathrm{mg}$ liraglutide and 16 units of insulin degludec [40]). In clinical practice, however, many patients are initiated on higher doses of iDegLira than the recommended daily starting dose (e.g. patients whose HbA1c is $>1 \%$ above target and who have a BMI $\geq 30 \mathrm{~kg} / \mathrm{m}^{2}$ ). This is consistent with the fact that patients receiving liraglutide mostly augmented/intensified with basal insulin (ESM Table S3). However, liraglutide-to-iDegLira treatment changes were categorized as switching, rather than augmentation/ intensification, in this analysis because robust data to support the latter classification were lacking (iDegLira dosing data were not available). Moreover, such a change would have had a negligible effect on the outcome of the analysis 
because only $2.0 \%$ of the liraglutide cohort changed to iDegLira during the period of the study.

Reasons for treatment changes represent a 'missing piece' in any retrospective claims study, including ours. The results of the ongoing TROPHIES study, which involves approximately 2100 patients with T2D who initiate their first injectable glucose-lowering therapy with dulaglutide or liraglutide, will provide not only persistence data from 24 months of prospective follow-up, but also reasons for significant treatment modifications [22].

\section{Limitations}

This analysis was subject to a number of limitations. First, this was a retrospective database study that used data from participating pharmacies only. As a result, the study population may not be fully representative of the French population with T2D, even though the number of participating pharmacies accounts for onethird of total pharmacies in France. Further limitations include the absence of a definitive diagnosis of $\mathrm{T} 2 \mathrm{D}$ and reliance on pre-index OAD treatment as a proxy for diagnosis. Also, as in other pharmacy claims databases, data relating to the reasons for treatment modifications are unknown and can only be hypothesized. Furthermore, because baseline data on which to base adjustments were not available, we did not adjust for any potential treatment selection bias or baseline confounding factors, and no formal statistical comparisons were performed. In addition, as mentioned earlier in the discussion and given that discontinuation was the predominant component of persistence, conducting a sensitivity analysis around the magnitude of the gap used in the definition of discontinuation might have helped interpret the results. Moreover, as in any study based on pharmacy claims data, it is possible that patients may not have taken the medications prescribed, even if prescriptions were filled. Conversely, patients may have stockpiled medication or filled prescriptions early.

\section{CONCLUSIONS}

The pharmacy claims data presented herein show that, in accordance with national guidelines, GLP-1 RAs were prescribed in combination with oral therapies and that augmentation/ intensification was mainly with insulin therapy. Overall, persistence with GLP-1 RA therapy was typically less than 1 year. However, there was evidence of substantial variation among individual GLP-1 RAs, with the highest persistence observed among patients receiving dulaglutide and the lowest among those receiving exenatide BID. The data on which our study is based do not include the reasons underlying treatment modification. However, the ongoing, 2-year, prospective, observational TROPHIES studywhich includes a French cohort-will provide this information in relation to patients who initiate their first injectable glucose-lowering therapy with dulaglutide or liraglutide.

\section{ACKNOWLEDGEMENTS}

Funding. Sponsorship for this study and the journal's Rapid Service Fee were funded by Eli Lilly and Company.

Medical Writing Assistance. The authors would like to thank Dr. Janet Douglas and Karen Goa (Rx Communications, Mold, UK) for medical writing assistance with the preparation of this article, funded by Eli Lilly and Company.

Authorship. All named authors meet the International Committee of Medical Journal Editors (ICMJE) criteria for authorship for this article, take responsibility for the integrity of the work as a whole, and have given their approval for this version to be published.

Authors' Contributions. Sarah Zimner Rapuch: conception and design of the work; analysis and interpretation of data for the work; drafting and critical revision of the manuscript for important intellectual content. Victoria Divino: conception and design of the work; acquisition, analysis and interpretation of data 
for the work; drafting and critical revision of the manuscript for important intellectual content. Kirsi Norrbacka: conception and design of the work; interpretation of data for the work; critical revision of the manuscript for important intellectual content. Kristina Boye: conception and design of the work; interpretation of data for the work; drafting of the manuscript. Jeremie Lebrec: analysis and interpretation of data for the work; drafting and critical revision of the manuscript for important intellectual content. Myriam Rosilio: interpretation of data for the work; critical revision of the manuscript for important intellectual content. Mitch DeKoven: conception and design of the work; acquisition and interpretation of data for the work; critical revision of the manuscript for important intellectual content. Bruno Guerci: analysis and interpretation of data for the work; critical revision of the manuscript for important intellectual content.

Prior Presentation. Some of the results included in this manuscript have previously been presented at the ISPOR Europe 2018 Conference (Barcelona, Spain; 10-14 November, 2018 [PDB-112]) and were published in Diabetes Therapy in 2019 (Divino V, Boye KS, Lebrec J, DeKoven M, Norrbacka K. GLP-1 RA treatment and dosing patterns among type 2 diabetes patients in six countries: a retrospective analysis of pharmacy claims data. Diabetes Ther. 2019;10:1067-88). We focus in more detail on the analysis for France in this publication.

Disclosures. Sarah Zimner Rapuch, Kirsi Norrbacka, Kristina Boye and Myriam Rosilio are employees of and minor shareholders in Eli Lilly and Company. Jeremie Lebrec is employed as a consultant for Eli Lilly and Company. Victoria Divino and Mitch DeKoven are employees of IQVIA, which received consulting fees for this study from Eli Lilly and Company. Bruno Guerci has served as a consultant, investigator and speaker for, and has received clinical research co-funding or grants from, the following pharmaceutical companies, organizations and learned societies: Bristol-Myers Squibb, Sanofi Aventis, GlaxoSmithKline, Novartis, Novo Nordisk, Eli Lilly, Johnson \& Johnson,
Astra Zeneca, Boehringer Ingelheim, Janssen, Intarcia, Metacure, Pfizer, MSD, Roche Diagnostic, Medtronic, Menarini Diagnostic, Abbott, Lifescan, Vitalaire, Dinno Santé and Ork'yn; AFSSAPS, CNAMTS, CEPS, SFD, SFE and NSFA

Compliance with Ethics Guidelines. Patient consent and ethics approval were not required for the use of these anonymized prescription data. The authors had permission to access the data from the IQVIA Real World Data [RWD] Adjudicated Pharmacy Claims database. Permission was granted by IQVIA.

Data Availability. The original de-identified data used in this analysis were obtained from and are the property of IQVIA. IQVIA has restrictions prohibiting the authors from making the data set publicly available. Interested researchers may contact IQVIA to apply to gain access to the study's data in the same way the authors obtained the data (see https://www. iqvia.com/contact/sf).

Open Access. This article is licensed under a Creative Commons Attribution-NonCommercial 4.0 International License, which permits any non-commercial use, sharing, adaptation, distribution and reproduction in any medium or format, as long as you give appropriate credit to the original author(s) and the source, provide a link to the Creative Commons licence, and indicate if changes were made. The images or other third party material in this article are included in the article's Creative Commons licence, unless indicated otherwise in a credit line to the material. If material is not included in the article's Creative Commons licence and your intended use is not permitted by statutory regulation or exceeds the permitted use, you will need to obtain permission directly from the copyright holder. To view a copy of this licence, visit http://creativecommons.org/licenses/by$\mathrm{nc} / 4.0 /$. 


\section{REFERENCES}

1. Davies MJ, D'Alessio DA, Fradkin J, et al. Management of hyperglycemia in type 2 diabetes, 2018. A consensus report by the American Diabetes Association (ADA) and the European Association for the Study of Diabetes (EASD). Diabetes Care. 2018;41: 2669-701.

2. Buse JB, Wexler DJ, Tsapas A, et al. 2019 Update to: Management of hyperglycemia in type 2 diabetes, 2018. A consensus report by the American Diabetes Association (ADA) and the European Association for the Study of Diabetes (EASD). Diabetes Care. 2020;43:487-93.

3. American Diabetes Association. 9. Pharmacologic approaches to glycemic treatment: standards of medical care in diabetes-2020. Diabetes Care. 2020;43 Suppl 1:S98-S110.

4. Haute Autorité de Santé. Stratégie médicamenteuse du contrôle glycémique du diabète de type 2 . Recommandation de bonne pratique-mis en ligne le 04 avr. 2013. https://www.has-sante.fr/jcms/c_ 1022476/fr/strategie-medicamenteuse-du-controleglycemique-du-diabete-de-type-2. Accessed 2 February 2021.

5. Cramer JA, Roy A, Burrell A, et al. Medication compliance and persistence: terminology and definitions. Value Health. 2008;11:44-7.

6. Holmes EA, Morrison VL, Hughes DA. What influences persistence with medicines? A multinational discrete choice experiment of 2549 patients. Br J Clin Pharmacol. 2016;82:522-31.

7. Garnero TL, Davis NJ, Perez-Nieves M, et al. Insulin non-persistence among people with type 2 diabetes: how to get your patients to stay on insulin therapy. Postgrad Med. 2018;130:394-401.

8. Mody R, Grabner M, Yu M, et al. Real-world effectiveness, adherence and persistence among patients with type 2 diabetes mellitus initiating dulaglutide treatment. Curr Med Res Opin. 2018;34:995-1003.

9. Wei W, Pan C, Xie L, Baser O. Real-world insulin treatment persistence among patients with type 2 diabetes. Endocr Pract. 2014;20:52-61.

10. Hamersky CM, Fridman M, Gamble CL, Iyer NN. Injectable antihyperglycemics: A systematic review and critical analysis of the literature on adherence, persistence, and health outcomes. Diabetes Ther. 2019;10:865-90.

11. Gatwood JD, Chisholm-Burns M, Davis R, et al. Differences in health outcomes associated with initial adherence to oral antidiabetes medications among veterans with uncomplicated type 2 diabetes: a 5-year survival analysis. Diabet Med. 2018;35:1571-9.

12. Guerci B, Chanan N, Kaur S, Jasso-Mosqueda JG, Lew E. Lack of treatment persistence and treatment nonadherence as barriers to glycaemic control in patients with type 2 diabetes. Diabetes Ther. 2019;10:437-49.

13. Divino V, Boye KS, Lebrec J, DeKoven M, Norrbacka K. GLP-1 RA treatment and dosing patterns among type 2 diabetes patients in six countries: a retrospective analysis of pharmacy claims data. Diabetes Ther. 2019;10:1067-88.

14. Divino V, DeKoven M, Hallinan S, et al. GLP-1 RA treatment patterns among type 2 diabetes patients in six European countries. Diabetes Ther. 2014;5: 499-520.

15. Divino V, DeKoven M, Khan FA, Boye KS, Sapin H, Norrbacka K. GLP-1 RA treatment patterns among type 2 diabetes patients in five European countries. Diabetes Ther. 2017;8:115-28.

16. Alatorre C, Fernández Landó L, Yu M, et al. Treatment patterns in patients with type 2 diabetes mellitus treated with glucagon-like peptide-1 receptor agonists: Higher adherence and persistence with dulaglutide compared with once-weekly exenatide and liraglutide. Diabetes Obes Metab. 2017;19:953-61.

17. Federici MO, McQuillan J, Biricolti $G$, et al. Utilization patterns of glucagon-like peptide-1 receptor agonists in patients with type 2 diabetes mellitus in Italy: a retrospective cohort study. Diabetes Ther. 2018;9:789-801.

18. Mody R, Huang Q, Yu M, et al. Dulaglutide has higher adherence and persistence than liraglutide and exenatide QW-one-year follow-up from U.S. real-world data. Diabetes. 2018;67 Suppl 1:1264-P. https://doi.org/10.2337/db18-1264-P.

19. Otto T, Myland M, Jung H, Lebrec J, Richter $H$, Norrbacka K. Utilization patterns of glucagon-like peptide- 1 receptor agonists in patients with type 2 diabetes mellitus in Germany: a retrospective cohort study. Curr Med Res Opin. 2019;35:893-901.

20. Fagot-Campagna A, Fosse S, Roudier C, et al. Caractéristiques, risque vasculaire et complications chez les personnes diabétiques en France métropolitaine: d'importantes évolutions entre Entred 2001 et Entred 2007. BEH Thématique. 2009;42-43:450-5.

21. Tiv M, Viel JF, Mauny F, et al. Medication adherence in type 2 diabetes: the ENTRED study 2007, a 
French population-based study. PLoS One. 2012;7: e32412.

22. García-Pérez LE, Sapin H, Norrbacka K, et al. The real-world observational prospective study of health outcomes with dulaglutide \& liraglutide in type 2 diabetes patients (TROPHIES) -Design and baseline characteristics. ISPOR Europe 2019, Copenhagen, 2-6 November 2019. PDB116.

23. Gelhorn HL, Poon JL, Davies EW, Paczkowski R, Curtis SE, Boye KS. Evaluating preferences for profiles of GLP-1 receptor agonists among injectionnaïve type 2 diabetes patients in the UK. Patient Prefer Adherence. 2015;9:1611-22.

24. Boye KS, Matza LS, Stewart KD, et al. Patient preferences and health state utilities associated with dulaglutide and semaglutide injection devices among patients with type 2 diabetes in Italy. J Med Econ. 2019;22:806-13.

25. Thieu VT, Robinson S, Kennedy-Martin T, Boye KS, Garcia-Perez LE. Patient preferences for glucagonlike peptide 1 receptor-agonist treatment attributes. Patient Prefer Adherence. 2019;13:561-76.

26. Matza LS, Boye KS, Stewart KD, et al. Assessing patient PREFERence between the dulaglutide pen and the semaglutide pen: A crossover study (PREFER). Diabetes Obes Metab. 2020;22(3):355-64.

27. Tran AM, Sand PK, Seitz MJ, Gafni-Kane A, Zhou Y, Botros SM. Does physician specialty affect persistence to pharmacotherapy among patients with overactive bladder syndrome? Int Urogynecol J. 2017;28:409-15.

28. Roussel R, Charbonnel B, Behar M, Gourmelen J, Emery C, Detournay B. Non-persistence of GLP-1 analogues in type 2 diabetes in France. American Diabetes Association Congress, San Diego, 9-13 June 2017. Poster 1131-P.

29. Roussel R, Charbonnel B, Behar M, Gourmelen J, Emery C, Detournay B. Persistence with insulin therapy in patients with type 2 diabetes in France: an insurance claims study. Diabetes Ther. 2016;7: 537-49.

30. Van Wijk BL, Klungel OH, Heerdink ER, de Boer A. Refill persistence with chronic medication assessed from a pharmacy database was influenced by method of calculation. J Clin Epidemiol. 2006;59: 11-7.

31. Guerci B, Charbonnel B, Gourdy P, et al. Efficacy and adherence of glucagon-like peptide-1 receptor agonist treatment in patients with type 2 diabetes mellitus in real-life settings. Diabetes Metab. 2019;45:528-35.

32. Bettge K, Kahle M, Abd El Aziz MS, Meier JJ, Nauck MA. Occurrence of nausea, vomiting and diarrhoea reported as adverse events in clinical trials studying glucagon-like peptide-1 receptor agonists: a systematic analysis of published clinical trials. Diabetes Obes Metab. 2017;19:336-47.

33. Detournay B, Cros S, Charbonnel B, et al. Managing type 2 diabetes in France: the ECODIA survey. Diabetes Metab. 2000;26:363-9.

34. Crowe S, Tully MP, Cantrill JA. The prescribing of specialist medicines: what factors influence GPs' decision making? Fam Pract. 2009;26:301-8.

35. Prosser $\mathrm{H}$, Almond $\mathrm{S}$, Wallet T. Influences on GPs' decision to prescribe new drugs-the importance of who says what. Fam Pract. 2003;20:61-8.

36. Marso SP, Daniels GH, Brown-Frandsen K, et al. Liraglutide and cardiovascular outcomes in type 2 diabetes. N Engl J Med. 2016;375:311-22.

37. Darmon P, Bauduceau B, Bordier L, et al. Prise de position de la Société Francophone du Diabète (SFD) sur la prise en charge médicamenteuse de l'hyperglycémie du patient diabétique de type 2 . Médecine Maladies Métaboliques. 2017;11:577-93. https://www.sfdiabete.org/sites/www.sfdiabete.org/ files/files/ressources/prise_de_position_sfd_diabete_ type_2.pdf.

38. Clements JN, Shealy KM. Liraglutide: an injectable option for the management of obesity. Ann Pharmacother. 2015;49:938-44.

39. Qin L, Chen S, Flood E, et al. Glucagon-like peptide1 receptor agonist treatment attributes important to injection-naïve patients with type 2 diabetes mellitus: a multinational preference study. Diabetes Ther. 2017;8:321-34.

40. Novo Nordisk. Xultophy ${ }^{\circledR}$ summary of product characteristics. 2019. https://www.ema.europa.eu/ en/documents/product-information/xultophyepar-product-information_en.pdf. Accessed 2 Feb 2021.

41. Novo Nordisk. Victoza ${ }^{\circledR}$ summary of product characteristics. 2014. https://www.ema.europa.eu/ en/documents/product-information/victoza-eparproduct-information_en.pdf. Accessed 2 Feb 2021. 